\title{
The Influence of Low Energy Impacts on the Static and Dynamic Response of a Foam Core Composite Wing
}

\author{
E. Aktaş, $,{ }^{1,2}, *$ M. Seaver,${ }^{3}$ J. M. Nichols,${ }^{3}$ S. T. Trickey ${ }^{3}$ And W. R. Davis ${ }^{4}$ \\ ${ }^{1}$ Former ASEE/NRL Postdoctoral Fellow \\ ${ }^{2}$ Izmir Institute of Technology, Department of Civil Engineering Urla Izmir 35430, Turkey \\ ${ }^{3}$ Naval Research Laboratory, Code 5673, 4555 Overlook Avenue Washington, DC 20375, USA \\ ${ }^{4}$ Naval Air Warfare Center, Aircraft Division, Patuxent River, MD 20670, USA
}

\begin{abstract}
This work describes damage detection efforts on a composite wing subject to a series of low-energy $(\sim 7 \mathrm{~J})$ impacts. Two airfoils with fundamentally different damage scenarios were considered. The first damage scenario produced no visible signs of damage on the wing surface following eight impacts. A duplicate wing, subjected to a similar series of impacts, was investigated using flash thermography and subsequently autopsied. The flash thermography showed small, localized damage in the skin, but gave no information about core damage. The autopsy showed core/skin disbonding at both interfaces that varied with the number of impacts, core crushing, and a through the core shear crack. No clear changes to the static or dynamic wing response were observed for this scenario. The second damage scenario involved cracking of the wing skin. While damage quantification was not undertaken for this scenario, both static and dynamic changes in wing response were observed. An analytical model of the wing is presented which helps explain the observed behaviors of the two damage scenarios.
\end{abstract}

Key Words: Structural Health Monitoring (SHM), fiber optic sensors, non-destructive testing, sandwich composite airfoil, low velocity impact damage, delamination.

\section{INTRODUCTION}

$\mathbf{T}$ HE current state-of-health of a structure is of great concern for owners since hidden damage may jeopardize the structural integrity leading to a sudden, catastrophic failure. Thus, a reliable, automated means of detecting damage in its early stages would allow for condition-based maintenance as opposed to time-based maintenance schedules, which should result in considerable savings on maintenance and significant drop in life cycle costs of the structure. For example, it has been estimated that actual loads monitoring could increase the useful life of the F/A-18 aircraft by roughly $50 \%$ resulting in a savings of $\$ 11.7$ billion dollars in new procurements. As a result of such motivation, Structural Health Monitoring (SHM) has attracted a great amount of attention from researchers and owners working to maintain the structural integrity or verify the expected conditions (Doebling et al., 1996; Soon et al., 2003).

As part of the effort in SHM, numerous damage detection metrics have been proposed and shown, at least in laboratory tests, the ability to sensitively

*Author to whom correspondence should be addressed.

E-mail: enginaktas@iyte.edu.tr

Figures 1-13 appear in color online: http://jim.sagepub.com detect damage. As a result a number of nondestructive techniques have been developed such as visual, acoustic emission (Sundaresan et al., 2002), thermography (Shih et al., 2000), eddy-current (Banks et al., 2002), ultrasonic (Tuzzeo and Lanza di Scalea, 2001), etc. Most of these techniques work well when there is a suspected damage location, or 'hot spot'; but are impractical to apply an entire structure, such as an airplane, ship, or bridge. An alternative approach is to monitor the structure's global response to ambient or applied loading and render a diagnosis, damaged, or undamaged. To this end a variety of techniques have been applied, whereby the practitioner monitors the vibrations for changes to certain damage-sensitive features (e.g., modal properties). A summary review of existing vibration-based techniques can be found in Soon et al. (2003) and Doebling et al. (1998). A robust approach that works in all cases has not been found. Each method has its own advantages and disadvantages and the complexity of real life structures may dictate a combined application of these methods, rather than a single one. Selection of a particular detection strategy requires a solid understanding of the damage mechanism and how it influences both the static and dynamic properties of the structure. Thus, the goal of this work is to determine when damage can be detected 
using global vibrations and to relate that detection limit to the amount and type(s) of damage present. Development of a mathematical model helps us to understand the connection between the types of damage and the response of the wing.

Due to their high strength-to-weight ratio and superior resistance to corrosion, composites are regularly used in aerospace engineering. One application is in unmanned aerial vehicles (UAVs), which are remotely piloted or self-piloted aircraft that can carry payloads such as cameras, sensors, communications equipment, etc. They have been widely used in a reconnaissance and intelligence-gathering roles. Many times they may be required to fly back-to-back missions where, upon landing, a quick inspection and maintenance are required before being sent out on the next mission. There have been incidents reported where premature failure of wing resulted in losing the vehicle (Wang et al., 2005). Barely visible damage induced during maintenance, such as a tool dropping on the wing, etc. or during a mission such as hail hitting the wing or a bird strike may jeopardize the integrity of the vehicle and the mission. For example, if a tool weighing $1 \mathrm{~kg}$ falls one meter and hits the wing, the impact energy would be about $9.8 \mathrm{~J}$. In a regular visual inspection, this problem might be overlooked, since there could be no sign of damage apparent on the wing surface.

While the literature contains many reports on impact damage to sandwich composite plates and beams, there are a few that offer specific guidance for this effort using low energy $(\sim 7 \mathrm{~J})$ impacts on a foam core sandwich wing. The major difference is that in the wing, the skin completely encases the foam core. Freeman et al. (2005) found that while 10,20 , and $30 \mathrm{~J}$ impacts did significant local damage they did not affect the fatigue performance of sandwich composite plates when loaded in four point bending. Their situation was similar to this report in that the damaged area was small relative to either the width or length of the structure. In contrast, Burman and Zenkert (1997) found reduced fatigue performance for plates with manufactured core/skin disbonds. While it is not stated in their report, we suspect that the manufactured disbonds spanned the width of the specimens. Core/skin disbonds were shown by Kulkarni et al. (2003) to represent both the initial (top interface) and final (bottom interface) damage stages in three-point bending, with a shear crack as the intermediate damage stage. The wing autopsy described below shows all three of these types of damage with the amounts depending on the number of impacts. None of the literature reports provide enough information to support an a priori prediction as to the extent of damage needed cause detectible changes in experiments such as those described subsequently.

An analytical model of the wing was developed to better understand the relative influences of the core and skin on the structural integrity of the wing. The skin controls the main flexural behavior of the wing; the foam core keeps the two face sheets at a distance from each other. For the isotropic slender beams having a doubly symmetric cross section, Euler-Bernoulli beam theory accurately predicts the behavior. The test wing, however, is composite, anisotropic, and has an unsymmetrical cross-section. For such a beam the governing equations become coupled (Volovoi et al., 2001). In other words, the bending moment will generate twist along the length of the beam in addition to flexural response. The unsymmetrical airfoil cross-section generates substantial coupling between bending and torsional modes especially in the dynamic response (Eslimy-Isfahany et al., 1996). The test wing used in this work is a little different than the wings studied in the literature; it is a filled thin walled closed cell sandwich composite with out a spar cap. The main flexural contributor is the skin with the core transmitting the shear between upper and lower skin. Helicopter rotor blades are generally built in such a way and modeled as filled box-beam (Lemanski and Weaver, 2005). However, instead of modeling the wing as a rectangular box beam, a simpler model that counts for the cross-sectional properties will be used herein following similar work on wind turbines (Stoddard et al., 2006). The model was used to predict the influence of two prominent types of damage on the wing's strain response. The model's predictions were evaluated by comparison with a series of static tip deflections.

The damage detection experiments involve a series of low energy impacts to a section of the wing surface. Both static and dynamic response data are collected from the wing using fiber Bragg grating $(\mathrm{FBG})$ strain sensors and accelerometers. Two wings with different impact scenarios were studied. In the first wing, the impacts are of such a magnitude that the skin of the wing remains intact i.e., the damage is not visible by inspection and no two impacts fall on the same location. For this scenario, both static and dynamic testing failed to show any damage-induced changes. Flash thermography and a subsequent autopsy were conducted on a duplicate wing undergoing similar impacts in an attempt to characterize the damage. The thermography shows limited damage within the laminate skin but no information about the condition of the foam core. The autopsy clearly reveals disbonding at both upper and lower skin/core interfaces, core crushing, and shear cracking despite the lack of visible damage at the surface. The second wing involved impacts of similar magnitude, but they were repeated on particular locations until the skin of the wing was broken. The process was then repeated at an adjacent location (Nichols et al., 2005). In this case, both static and dynamic properties of the wing become significantly altered, indicating the presence of damage. The model offers a clear explanation for the observed differences in wing response to the two damage scenarios. 


\section{MODELING}

In order to understand the relationship between damage and behavior, it is important to model the structure. Although, the unsymmetrical composite airfoil cross-section challenges the modeling efforts, even a simple and straightforward model can capture the key factors affecting the structure's response and provide a better understanding of the effects of damage. In this work, a simple elastic beam model is used to obtain a basic understanding of the wing behavior. In this case, the bending and shear centroids do not coincide with each other. Thus, the loads applied may result in torsion on the cross section. The wing cross-section properties were calculated using area-weighted flexural modulus, following the composite blade example presented in the report by Stoddard et al. (2006).

\section{Cross-section Description}

The LAM wing tested is a sandwich composite, composed of four layers of woven carbon fiber fabric as face sheet and foam core between them (Figure 1). These two parts of the cross section have different properties and play different roles in how they affect the behavior of the whole section. The stiffer face sheets are the main contributor to flexural behavior; in engineering calculations the contribution of the core to the flexural behavior is ignored. But in order to understand postdamage behavior of the wing, quantifying the contribution of the core is essential because the damage expected after impact(s) includes delamination between core and face and crushing of the core. Therefore, in the model the contribution of the core to the flexural behavior is also included.

The Bernoulli-Euler beam theory is used to capture the behavior of the beam. The assumptions of small

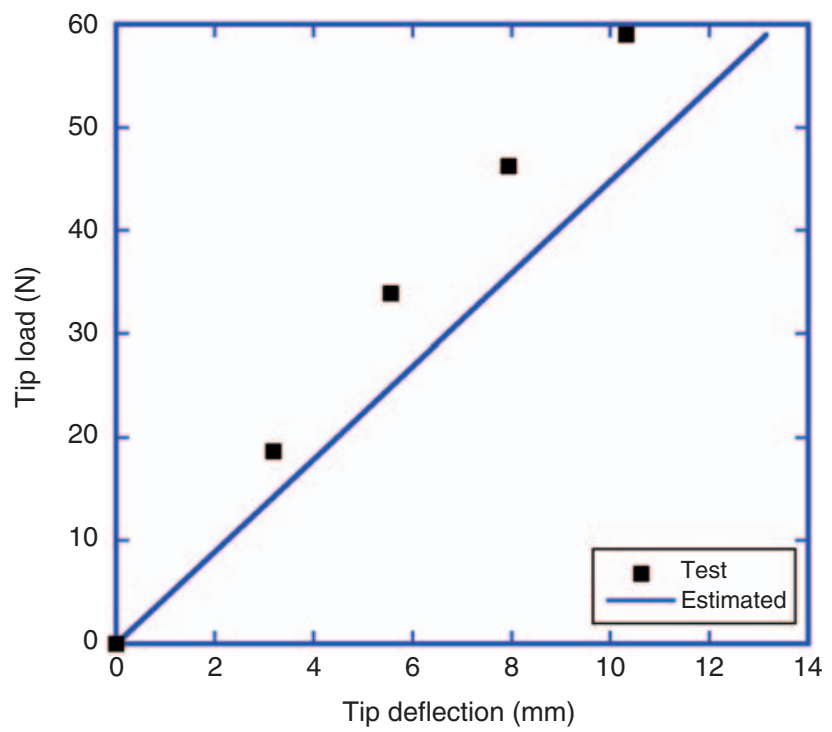

Figure 1. Comparison of test and model. deflections and plane sections remain plane are active. The response of the beam's bending axis can be calculated. The laminate properties of the skin and properties of foam core (as provided by the manufacturer) are tabulated in Table 1. The geometry of the wing dictated that wide-beam theory to be used to find the plate deflections under plane strain (Timoshenko and Goodier, 1970). The difference between wide-beam theory and regular beam theory involves replacing the modulus of elasticity with

$$
E_{\text {wide-beam }}=\frac{E_{\text {beam }}}{1-v_{12} v_{21}}
$$

where $v_{12}$ and $v_{21}$ are Poisson's ratios spanwise and chordwise, respectively, and $E_{\text {beam }}$ is the modulus of the elasticity along the beam axis.

\section{Section Area and Stiffness Properties}

To determine the section area for the model, the outer perimeter of the wing was measured taking the leading edge as the origin, $x$-axis pointing towards trailing edge along the chord-line, and the $y$-axis upward through the thickness. The inner perimeter of the skin was estimated by subtracting the factory defined skin thickness from the measured outer perimeter. All the sectional properties require integration throughout the cross-section. Therefore, the outer and inner perimeters are fitted with the polynomial in the following form:

$$
f(x)=a_{1} \sqrt{x}+a_{2} x+a_{3} x^{2}+a_{4} x^{3}+a_{5} x^{4}
$$

The polynomial was fitted for top and bottom separately. The fitted polynomial, $f(x)$, was used to determine the area, first area moment, and moment of inertia of the skin and core. Taking the first area moment with respect to $x$ - and $y$-axes, and using the area-weighted moduli, the bending centroid calculation is straight forward;

$$
\begin{aligned}
& \bar{X}_{T}=\frac{1}{E A}\left[E_{\text {skin }} M_{y \text { skin }}+E_{\text {core }} M_{y \text { core }}\right] \\
& \bar{Y}_{T}=\frac{1}{E A}\left[E_{\text {skin }} M_{x \text { skin }}+E_{\text {core }} M_{x \text { core }}\right]
\end{aligned}
$$

Table 1. The properties of the skin and foam core.

\begin{tabular}{llll}
\hline $\begin{array}{l}\text { Laminate properties } \\
\text { of 4-ply skin }\end{array}$ & \multicolumn{2}{c}{$\begin{array}{c}\text { Core } \\
\text { (Last-a-foam FR6706) }\end{array}$} \\
\hline$E_{1}$ & $34000 \mathrm{MPa}$ & $\rho$ & $96 \mathrm{~kg} / \mathrm{m}^{3}$ \\
$E_{2}$ & $17000 \mathrm{MPa}$ & $E_{\text {comp }}$ & $35 \mathrm{MPa}$ \\
$G_{12}$ & $17600 \mathrm{MPa}$ & $E_{\text {tension }}$ & $30 \mathrm{MPa}$ \\
$v_{12}$ & 0.716 & $v$ & 0.3 \\
$t$ & $0.71 \mathrm{~mm}$ & & \\
\hline
\end{tabular}


where, the $M_{x}$ and $M_{y}$ are for first moment of area with respect to $x$ - and $y$-axes, respectively. $E A$ stands for area-weighted moduli and can be evaluated as

$$
E A=E_{\text {skin }} A_{\text {skin }}+E_{\text {core }} A_{\text {core }}
$$

The section stiffness in both directions were then estimated using

$$
\begin{array}{r}
E I_{x \text { total }}=E_{\text {skin }}\left\{\left[I_{x \text { skin }}-A_{\text {skin }} \bar{Y}_{\text {skin }}^{2}\right]+A_{\text {skin }}\left[\bar{Y}_{\text {skin }}-\bar{Y}_{T}\right]^{2}\right\} \\
+E_{\text {core }}\left\{\left[I_{x \text { core }}-A_{\text {core }} \bar{Y}_{\text {core }}^{2}\right]+A_{\text {core }}\left[\bar{Y}_{\text {core }}-\bar{Y}_{T}\right]^{2}\right\} \\
E I_{y \text { total }}=E_{\text {skin }}\left\{\left[I_{y \text { skin }}-A_{\text {skin }} \bar{X}_{\text {skin }}^{2}\right]+A_{\text {skin }}\left[\bar{X}_{\text {skin }}-\bar{X}_{T}\right]^{2}\right\} \\
+E_{\text {core }}\left\{\left[I_{y \text { core }}-A_{\text {core }} \bar{X}_{\text {core }}^{2}\right]+A_{\text {core }}\left[\bar{X}_{\text {core }}-\bar{X}_{T}\right]^{2}\right\}
\end{array}
$$

The cross product of the section is estimated in a similar way. Then the principal axis orientation and values are estimated. The angle between the $X$ - and $Y$-axes and the principal axes is only $0.38^{\circ}$. The first terms in expressions for each direction given in Equation (1) reflect the contribution of the skin to the flexural rigidity. Although the moment of inertias for both the skin and core are the same order, because of the low modulus elasticity of the core, the contribution of it to the overall flexural rigidity is limited. For this case, the ratio of the flexural rigidity from core and skin is 0.65 and $0.37 \%$ for $x$-and $y$-directions, respectively. The model clearly shows (as expected) that the core does not provide stiffness for the flexural rigidity. On the other hand, the core does provide support to avoid local buckling of skin and keep the upper and lower skin apart to provide high moment of inertia.

\section{Load Test Verification and Deflection Calculation}

In order to investigate the agreement of the model with the real response, a series of load tests were performed and the applied tip load versus tip deflection graph was obtained (Figure 1). In the same plot the response attained from the model is also presented. Comparing the test results to the model; the flexural stiffness, EI deduced from the load test results is $412 \mathrm{Nm}^{2}$, where the $E I$ estimated from the model is $339 \mathrm{Nm}^{2}$. This reasonable agreement with the test results indicates sufficient accuracy in the model to understand the global behavior of the wing.

\section{EXPERIMENT}

A lingering air munition (LAM) wing was selected as the test structure for investigating the effect of low energy impact on foam core sandwich composites and showing the performance of strategies for detecting the related damage. The LAM wing is a sandwich composite, composed of four layers of woven carbon fiber fabric, an aluminum core where connected to the fuselage and a foam core for the rest of the wing. The wing measures $1320 \mathrm{~mm} \times 152.4 \mathrm{~mm} \times 13.4 \mathrm{~mm}$ and has an airfoil crosssection. An initial delamination between the core and skin was introduced during fabrication using Teflon tapes $(50 \mathrm{~mm} \times 12.5 \mathrm{~mm} \times 25.4 \mathrm{~mm} \times 12.5 \mathrm{~mm}$, respectively) symmetrically placed with respect to the wing's mounting points. A series of static and dynamic tests were performed on the wing before and after each impact to investigate any changes related to damage progression.

The wing was instrumented with nine FBG sensors and two accelerometers (A1 and A2 in Figure 2). In order to create similar boundary conditions as during a flight it was mounted on the shaker as if it was mounted on the fuselage. Using tacky wax, one accelerometer was attached at the mid-point of the wing to acquire the excitation and the other accelerometer was attached close to tip of the wing to monitor the wing's motion. One of the FBGs was placed on top of the damage area as a direct measure of damage. Unfortunately, this FBG was lost during the detaching and reattaching process to allow impacts. The remaining eight FBGs were used to acquire both static and dynamic strains.

In order to assess the influence of the damage on the structural properties of the wing, the damage was introduced progressively. The delaminated area was divided into eight sections and in each step a single impact is applied to one section, respectively (Figure 3). In order to test static performance the static testing rig shown in Figure 4 was used. Following each impact, a static test was performed to check for any changes in elastic properties of the wing. The wing was also tested statically one more time following the dynamic testing, but prior to next impact i.e., in each state of damage the wing was tested twice, statically with 15 dynamic measurements made between the two static tests. The tip deflection was introduced to the wing by adjusting the turnbuckle of the test rig and the strain data were acquired at tip deflections of 9.50, 15.9, 22.2, 25.4, 28.6, $31.8,34.9 \mathrm{~mm}$.

The damage progression was maintained by introducing low energy impacts using a swing arm impactor (Figure 5). The impactor registers the angular displacements during the course of impact, which was used to obtain the incident and rebound velocities and subsequently calculate both the impact energy, and energy deposited to the wing during the impact. Using the information from previous tests and running some trials on a duplicate wing, an approximate angle was established for damaging the core but not the skin. A release angle of $40^{\circ}$ resulted in incident energies near $9 \mathrm{~J}$ and deposited energies near $7 \mathrm{~J}$ but left visible changes in 


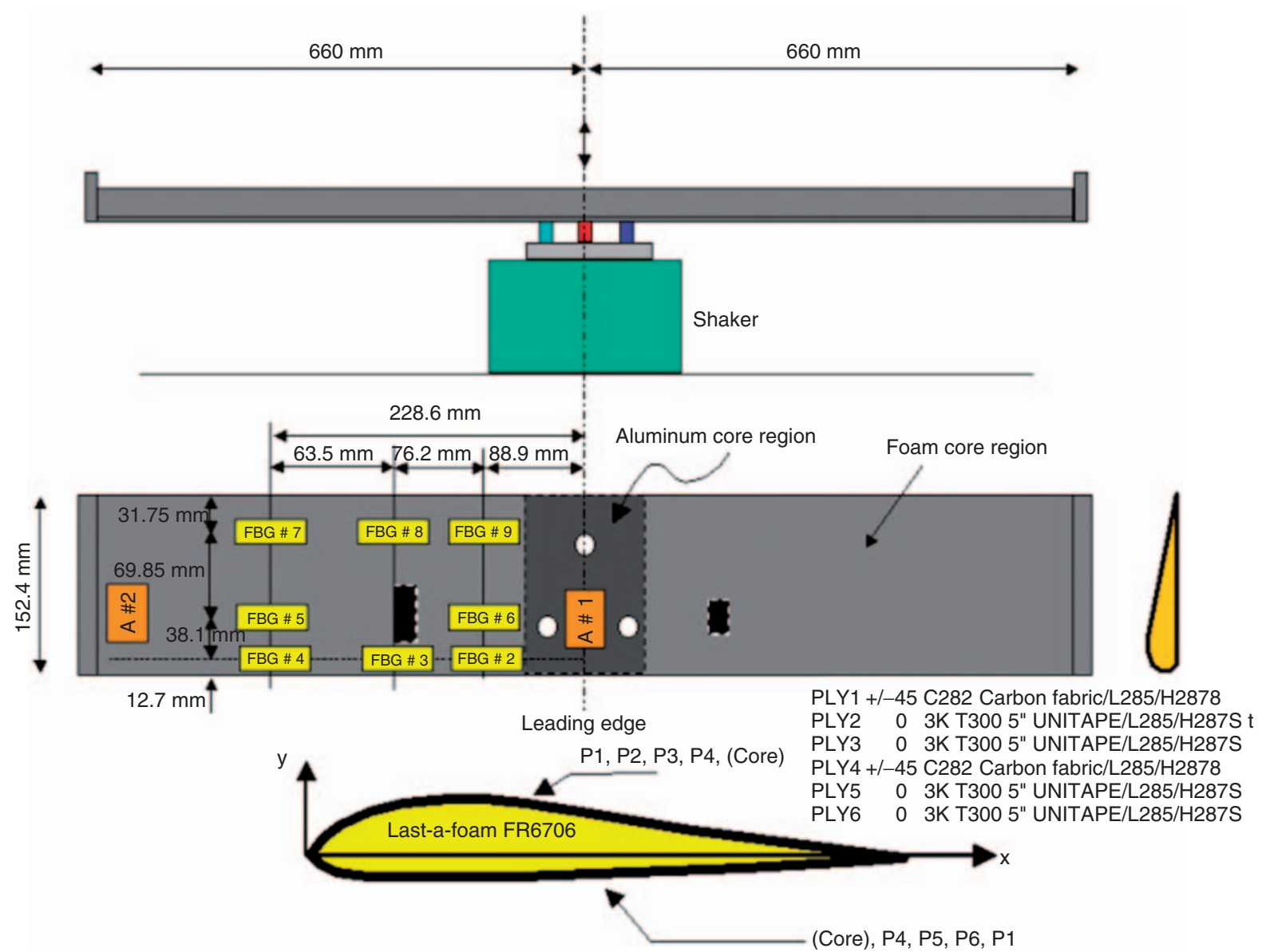

Figure 2. Test setup for the LAM wing. A1 and A2 indicate locations of the accelerometers. The black rectangles indicate the locations of the Teflon inserted between the skin and core.
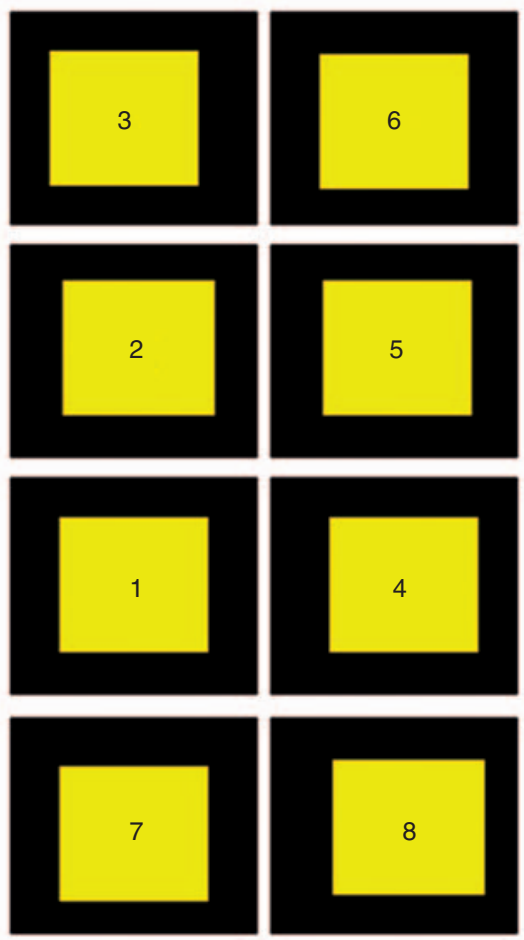

Figure 3. The sequence of impacts on the delaminated area.

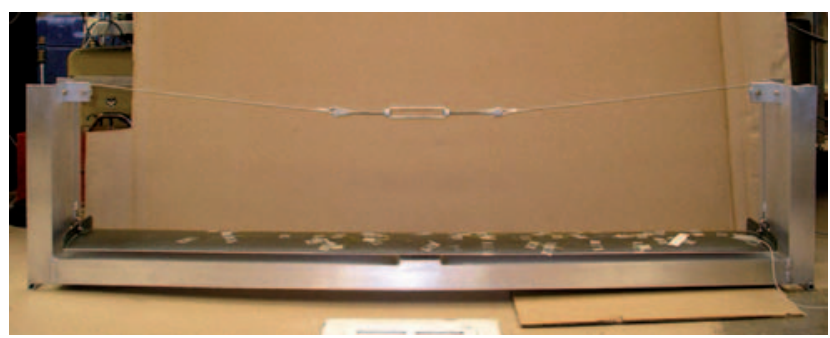

Figure 4. Static strain rig.

the skin. The energy deposited in the wing was estimated from the incident and rebound velocities deduced from the angular position acquired with respect to time.

The wing was impacted at the predetermined damage area eight times. Two representative angular position curves during impacts are presented in Figure 6. In order to compare these impacts to possible threats the wing might face, the energy deposited or impact energy was estimated using the expression

$$
E=\frac{1}{2} m L^{2}\left(\omega_{\mathrm{i}}^{2}-\omega_{\mathrm{r}}^{2}\right)
$$

where $m$ is the effective mass (Symon, 1971) of the tup, weight, and arm, $L$ is the swing arm length, and $\omega_{\mathrm{i}}$ and $\omega_{\mathrm{r}}$ 


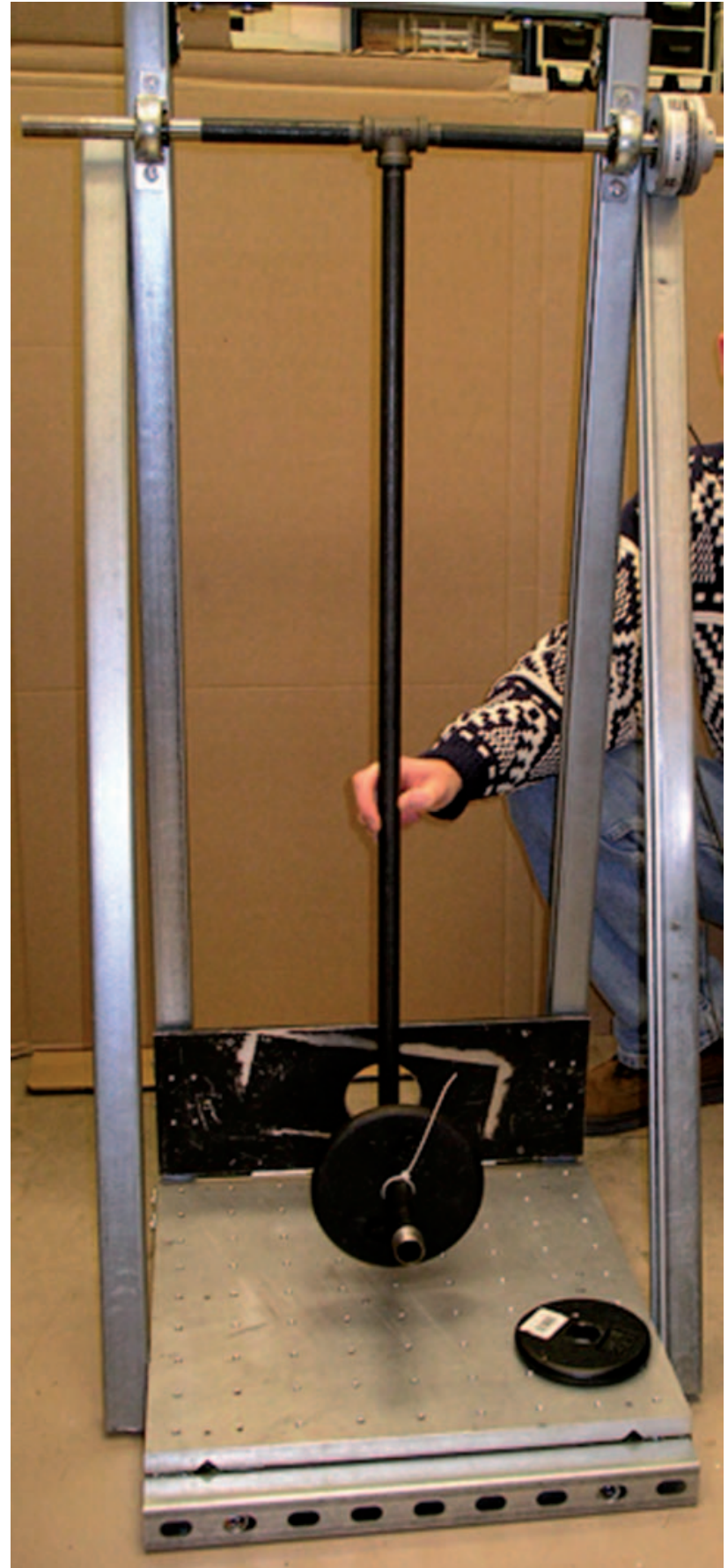

Figure 5. The impactor.

are incident and rebound angular velocities, respectively. The incident and rebound angular velocities were evaluated using the derivative of the angular position curve, before and after impact, respectively. The impact energy on the other hand simply is equal to kinetic energy at the impact instant. Table 2 shows the velocities and the estimated impact and deposited energies to the wing in each impact. The variation in rebound angular velocity is probably due to uncertainties in the support conditions of wing. The incident impact energies are equivalent to a $1 \mathrm{~kg}$ mass dropping at $1 \mathrm{~m}$ height to the wing.

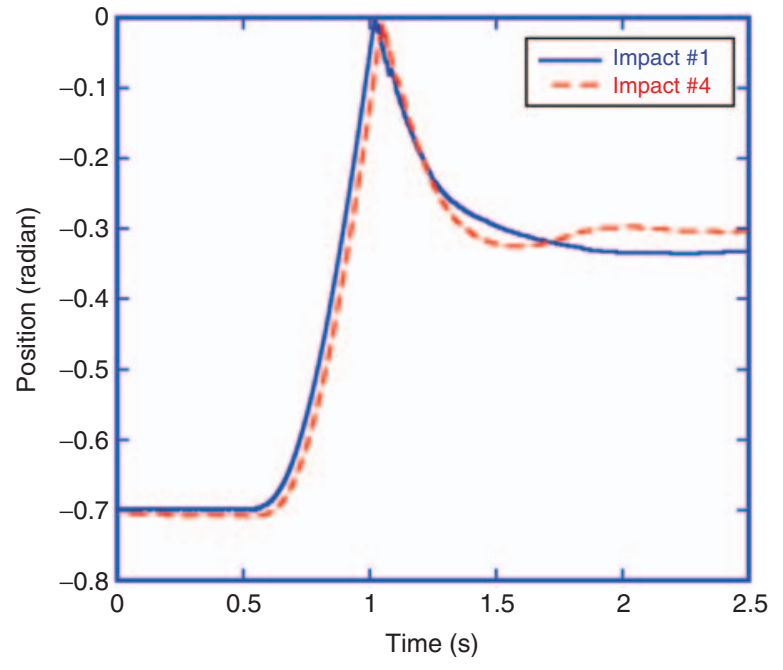

Figure 6. Representative data for impacts (Impact \# 1 and 4).

Table 2. Energy deposited on LAM wing in each impact.

\begin{tabular}{lcccc}
\hline $\begin{array}{l}\text { Impact } \\
\text { number }\end{array}$ & $\begin{array}{c}\text { Incident } \\
\text { ang. vel. } \\
\omega_{\text {i }}(\mathbf{r a d} / \mathbf{s})\end{array}$ & $\begin{array}{c}\text { Rebound } \\
\text { ang. vel. } \\
\omega_{\mathbf{r}}(\mathbf{r a d} / \mathbf{s})\end{array}$ & $\begin{array}{c}\text { Impact } \\
\text { energy } \\
\mathbf{( J )}\end{array}$ & $\begin{array}{c}\text { Energy } \\
\text { deposited } \\
\mathbf{( J )}\end{array}$ \\
\hline 1 & 2.58 & 1.48 & 9.59 & 6.43 \\
2 & 2.57 & 1.32 & 9.51 & 7.00 \\
3 & 2.50 & 1.13 & 9.00 & 7.16 \\
4 & 2.57 & 1.46 & 9.51 & 6.44 \\
5 & 2.57 & 1.54 & 9.51 & 6.10 \\
6 & 2.57 & 1.39 & 9.51 & 6.73 \\
7 & 2.57 & 1.42 & 9.51 & 6.61 \\
8 & 2.66 & 1.39 & 10.19 & 7.41 \\
\hline
\end{tabular}

The dynamic response of the wing to applied excitation was also measured. The input excitation was an independent identically distributed Gaussian with a $1 \mathrm{kHz}$ bandwidth. For each damage scenario a total of 15 response signals were collected in order to assess reproducibility. Data were collected at a sampling rate of $2 \mathrm{kHz}$ for $\sim 40 \mathrm{~s}$ to give strain response time series of $\sim 80,000$ points. These data were then used to explore changes in the vibrational properties of the wing as damage was incurred.

\section{DETERMINATION OF 'HIDDEN' DAMAGE}

A critical feature in experiments such as these is to determine the actual damage developed in the structure. Two approaches were tried on a duplicate wing subjected to similar impacts. On this duplicate wing the number of impacts was varied with location such that a series of damaged areas were obtained. These areas were separated spanwise by $50-75 \mathrm{~mm}$ in an attempt to minimize cross talk between the different areas. Thus, when analysis was started on the duplicate wing it contained six damaged areas with the different locations containing 1, 2, 3, 6, and 8 impacts Figure 7(a). 


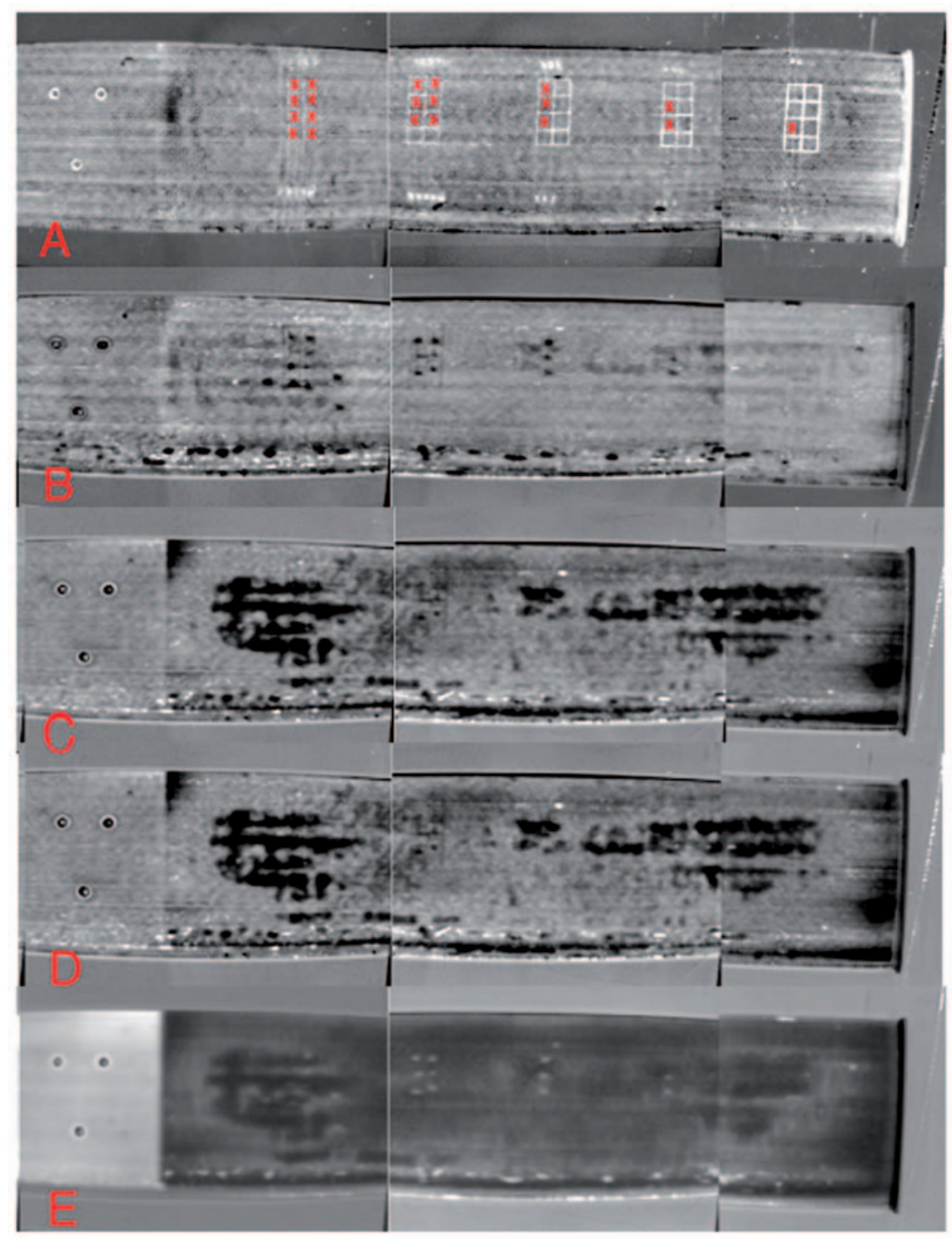

Figure 7. Thermographic images of the duplicate wing prior to disection. The images were taken $0.03,0.50,0.70,1.00$, and $1.50 \mathrm{~s}$ after the excitation flash.

The first test was nondestructive using flash thermography (Krishnapillai, 2005). In flash thermography, a short duration, high intensity flash heats the surface of the structure. Then an infrared camera captures a series of images recording the time evolution of the temperature. Damage shows up as local temperature changes that differ from adjacent areas due to the effects of the damage on the thermal diffusivity. Figure 7 shows the temperature change information $0.03,0.50,0.70,1.00$, and $1.50 \mathrm{~s}$ after the flash. The images in Figure 7 are composite images made by combining data at a given $\Delta t$ from three separate measurements along one half of the wing. The red $x$ 's in Figure 7(a) were added subsequently and indicate the locations of the impacts. Figure 7(b) clearly shows thermal diffusivity changes (small black dots) due to impacts for the 8, 6, 3, and 2 impact scenarios. Other locations with varying thermal diffusivity are related to manufacturing details. The impact locations are obscured in 7(c) and (d) by effects presumed to be in the glue region between the skin and core. In Figure 7(e), most of the wing's temperature is decaying at a constant rate, with the exception of some of the impact areas and the aluminum center section. Since the thermal diffusivity of the foam core is very close to that of air, we did not expect to detect physical separation between the core and skin due to core 
crushing with this technique. Thus, the thermal diffusivity changes associated with the impacts seen in images 7 (b) and (e) are probably damage within the skin layers. This interpretation is supported by the visual assessment of the damage after different numbers of impacts obtained by dissecting the wing using a small-toothed band saw. In the dissection, regions near the impacts were sliced into 5-6 $\mathrm{mm}$ thick sections, with larger sections spanning the gaps between impact regions. Figure 8 contains photographs of cross sections from the region directly under the impacts. From top to bottom the number of impacts was $1,2,3,6$, and 8. Damage after one impact included disbonding along the top skin/ core boundary, core crushing and a $45^{\circ}$ shear crack that completely spans the thickness. The next two impacts increase the core/skin disbonding outside of the impact region along the top interface, core crushing directly below the impact site, and extend the disbond along the bottom skin towards the leading edge. The extension of this crack is hard to see unless torque is applied across the crack. It's worth noting that the damage increases at this stage mimic the fatigue results seen by Kulkarni et al. (2003). Following six impacts a second throughthe-thickness crack has appeared near the trailing edge of the impact region. Following eight impacts the core has become delaminated from much of the bottom edge of the wing, resulting in a roughly rectangular region of core that is completely disconnected from the skin.

There is one significant difference between the autopsy and test wings. The test wing had a $4 \mathrm{~cm} \times 1 \mathrm{~cm}$ piece of Teflon inserted between the skin and the core during manufacturing. This Teflon piece is directly underneath the region where impacts $1-3$ and 7 were placed. Because we do not have additional wings with the Teflon inserts, we were not able to autopsy an identical specimen. However, the autopsy specimen was manufactured using identical materials without the Teflon insert. We expect that the Teflon insert will have some effect on the damage extent and progression but at this time we have no way of knowing what those differences are.

\section{DETECTION OF 'HIDDEN' DAMAGE}

The strains acquired with FBGs 4 and 5 at different levels of tip deflection during the static tests are shown in Figure 9 as representative cases. According to the model, there should be little, if any, change in the static strains for the wing when the damage is such that the skin remains intact. Indeed, Figure 9 shows no substantial change in static strain performance for any damage scenarios. The maximum observed change in the static strain was $<10 \%$ for the highest strain level following eight impacts. The highest strain levels are observed at FBGs 5 and 6, which are attached to the wing near the maximum thickness, and are therefore the

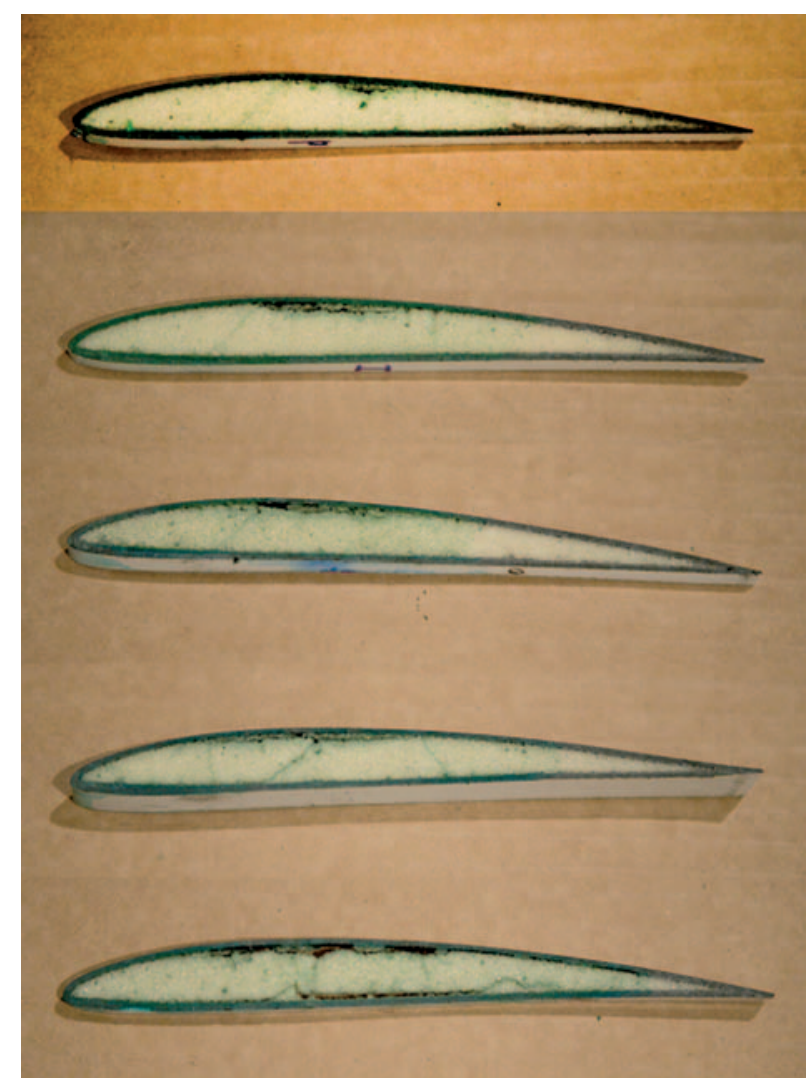

Figure 8. Wing autopsy pictures showing core damage under the impact region after 1, 2, 3, 6, and 8 impacts (top to bottom, respectively).

farthest away from the neutral axis. The rest of the FBGs experience lower strains. For each damage case, two static strain measurements were recorded. In many cases, the two results differ by about $50 \mu \varepsilon$. Taking this value as the measurement precision indicates that only for the two largest tip deflections and impacts $6-8$ are there changes in strain that exceed the measurement error. Thus, Figure 9 suggests that linear elastic behavior prevails throughout the all damage states for static loading.

Next, the wing's dynamic strain response was analyzed. This study focused on wide band Gaussian excitation, because the higher modes up to $1 \mathrm{kHz}$ might be excited and it is likely to pick up changes due to local damage on higher modes. Comparison of the Frequency Response Functions (FRF) of the FBGs at different damage levels does not suggest any damage [Figure 10(a)]. There are not any substantial differences among the FRFs to be interpreted as damages. This suggests that the global behavior is also unaffected by the damage sustained in the core.

\section{DETECTING VISIBLE SKIN DAMAGE}

Both static and dynamic testing were also carried out on a second wing, which suffered damage to the skin as 
(a)

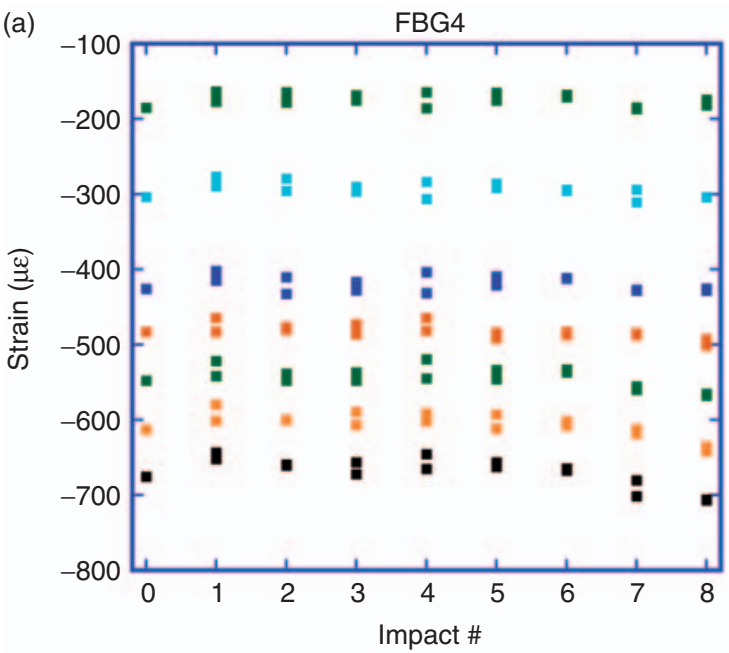

(b)

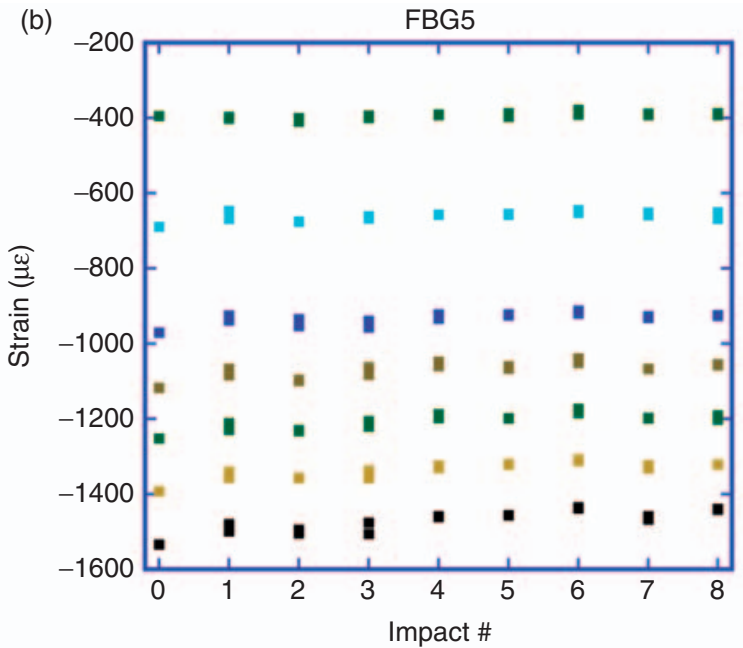

Tip deflection $(\mathrm{mm})$

Tip deflection $(\mathrm{mm})$

$34.9=31.8=28.6=25.4=22.2=15.88=9.53$

- $34.9=31.8=28.6=25.4=22.2=15.88=9.53$

Figure 9. Static strains for FBGs (a) 4 and (b) 5 as functions of tip deflection and number of impacts.

(a)

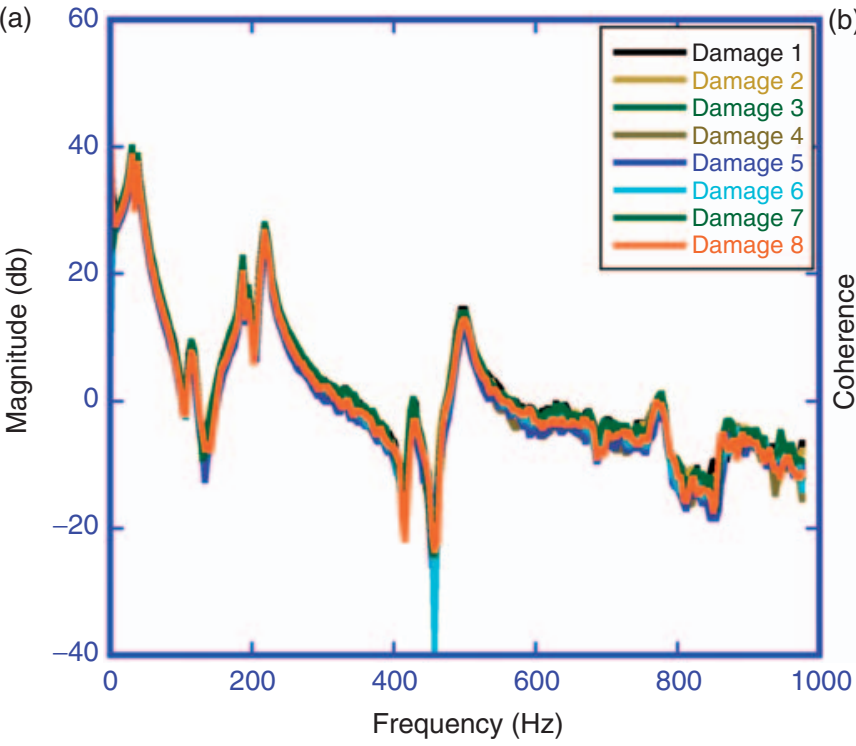

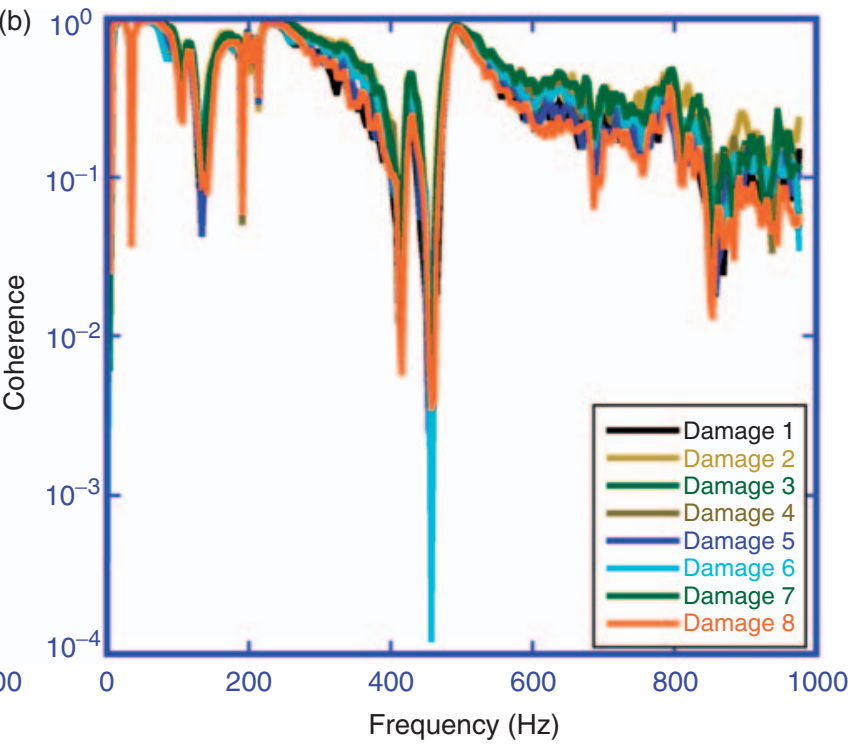

Figure 10. (a) The FRF and (b) coherence for all damage cases.
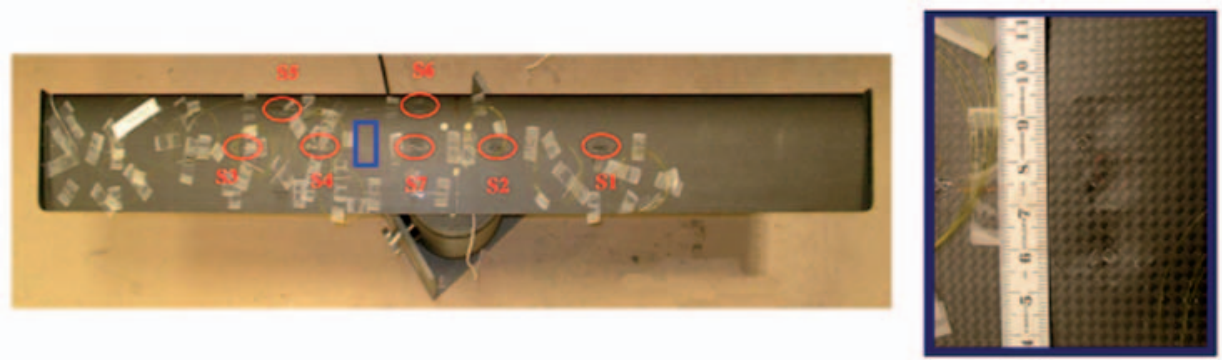

Figure 11. Previous test wing with skin damage.

well as to the core. For this wing consecutive impacts were performed until the skin cracked (Figure 11). Based on the model, once the integrity of the skin is compromised the wing should lose a significant amount of stiffness.
Indeed this is the case as the static test data shows drastic changes after the skin crack forms (Figure 12). The crack is formed at the top skin, where the wing surface is under compression. The crack formation at the damage location over certain level of stresses 

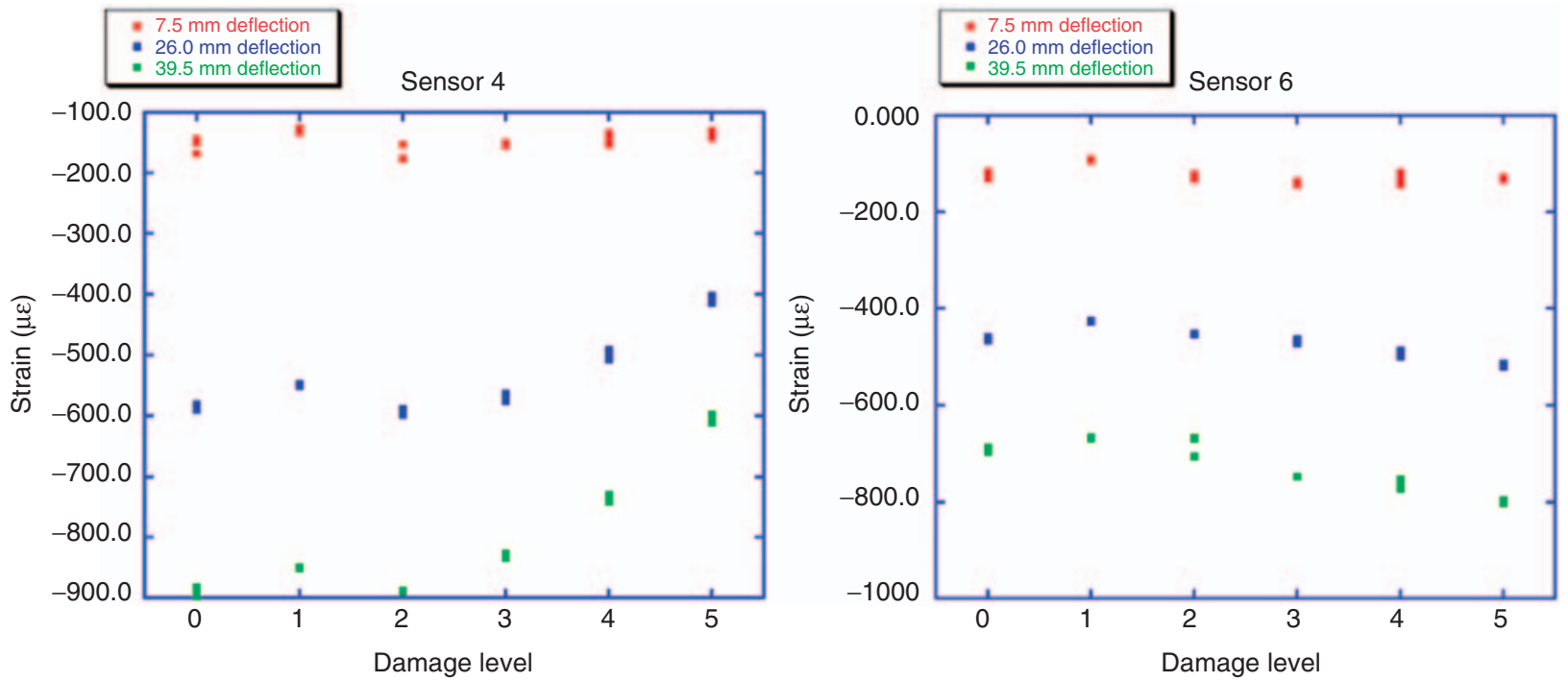

Figure 12. Static test results for the previously tested wing.

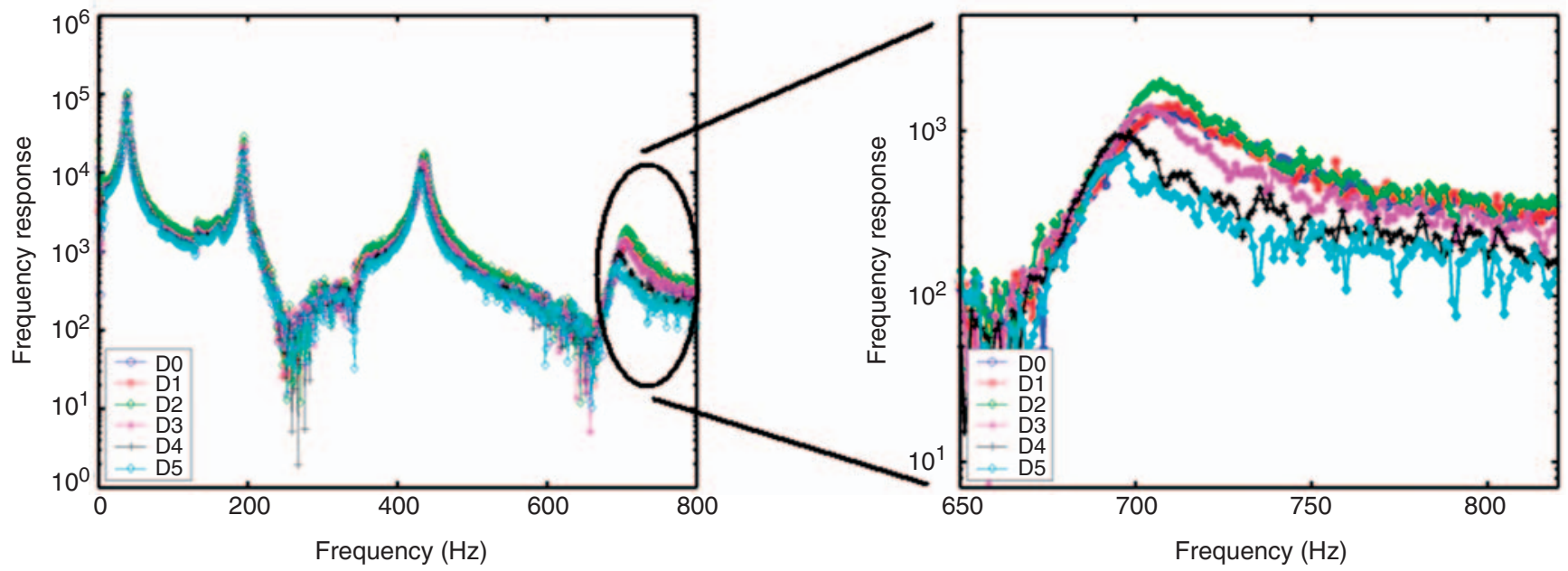

Figure 13. FRFs of the previously tested wing.

behaves like hinge, therefore neighboring locations start experiencing higher strains compared to the no skin crack case. The changes around 420 and $700 \mathrm{~Hz}$ in the FRFs also suggest that this type of damage is detectable with dynamic vibration data (Figure 13). As the wing becomes damaged and loses stiffness, the natural frequencies begin to drop. For the higher modes this effect is more pronounced (see Figure 13, right plot).

\section{CONCLUSIONS}

The detection of barely visible impact damage on foam core sandwich UAV wing due to low energy impacts has been presented. Following each $\sim 7 \mathrm{~J}$ impact, the wing was tested both statically and dynamically. The static tests did not show substantial changes in the response due to the impacts. FRFs also do not show any change due to damage. On the other hand, a similar wing suffering skin damage shows the signs of damage in both static and dynamic response data.

The extent of damage was investigated using flash thermography and sectioning of a similar wing. The sectioning showed a clear progression of damage in the foam core with increasing number of impacts in the absence of visible external manifestations. The flash thermography indicated small isolated amounts of damage in the skin of the wing but gave no evidence of the core damage. Based on the modeling effort and the experiment, we conclude that any damage detection strategy based on measuring either static or vibrational strain response data is unlikely to succeed until the integrity of the composite skin is compromised.

Future research will concentrate on increasing the damage in the skin and determining the threshold for detecting the damage using both static and dynamic strain measurements. 


\section{REFERENCES}

Banks, H.T., Joyner, M.T., Wincheski, B. and Winfree, W.P. 2002. "Real Time Computational Algorithms for Eddy-current Base Damage Detection," Inverse Problems, 18:795-823.

Burman, M. and Zenkert, D. 1997. "Fatigue of Foam Core Sandwich Beams-2: Effect of Initial Damage," Int. J. Fatigue, 19:563-578

Doebling, S.W., Farrar, C.R., Prime, M.B. and Shevitz, D.W. 1996. "Damage Identification and Health Monitoring of Structural and Mechanical Systems from Changes in their Vibration Characteristics: A Literature Review," Los Alamos National Laboratory Report, LA-13070-MS, Los Alamos, NM.

Doebling, S.W., Farrar, C.R. and Prime, M.B. 1998. "A Summary Review of Vibration-based Identification Methods," Shock and Vibration Digest, 205:631-645.

Eslimy-Isfahany, S.H.R., Banarjee, J.R., and Sobey, A.J. 1996. "Response of a Bending-Torsion Coupled Beam to Deterministic and Random Loads," Journal of Sound and Vibration, 195(2):267-283.

Freeman, B., Schwinger, E., Mahinfalah, M. and Kellogg, K. 2005. "The Effect of Low-velocity Impact on the Fatigue Life of Sandwich Composites," Composite Structures, 70:374-381.

Kulkarni, N., Mahfuz, H., Jeelani, S. and Carlsson, L.A. 2003. "Fatigue Crack Growth and Life Prediction of Foam Core Sandwich Composites Under Flexural Loading," Composite Structures, 59:499-505.

Krishnapillai, M., Jones, R., Marshall, I.H., Bannister, M. and Rajic, N. 2005. "Thermography as a Tool for Damage Assessment," Composite Structures, 67:149-155.

Lemanski, S. and Weaver, P. 2005. "Flap-torsion Coupling in Sandwich Beams and Filled Box Sections," Thin-Walled Structures, 43:923-955.
Nichols, J.M. et al. 2005. "Detecting Impact Damage in Experimental Composite Structures: An Information-theoretic Approach," Smart Materials and Structures, 14:1-11.

Shih, J.K.C., Delpak, R., Hu, C.W. Plassmann, P., Wawrzynek, A. and Kogut, M. 2000. "Thermographic Nondestructive Testing Damage Detection for Metals and Cementitious Materials," J. Imaging Sci., 48:33-43.

Soon, H., Farrar, C.R., Hemez, F.M., Shunk, D.D., Stinemates, D.W and Nadler, B.R. 2003. "A Review of Structural Health Monitoring Literature: 1996-2001," Los Alamos National Laboratory Report, LA-13976-MS, Los Alamos, NM.

Stoddard, F., Nelson, V., Starcher, K.M. and Andrews, B. 2006. "Determination of Elastic Twist in Horizontal Axis Wind Turbines (HAWTS) Final Report: August 1989," Subcontract Report, NREL/SR-500-12087.

Sundaresan, M.J., Ghoshal, A. and Schulz, M.J. 2002. "A Continuous Sensor for Damage Detection in Bars," Smart Materials and Structures, 11:475-488.

Symon, K.R. 1971. Mechanics, 3rd edn, Addison-Wesley, Reading, MA.

Timoshenko, S.P. and Goodier, J.N. 1970. Theory of Elasticity, 3rd edn, McGraw-Hill, New York, NY.

Tuzzeo, D. and Lanza di Scalea, F. 2001. "Non-contact Air-coupled Ultrasonic Guided Waves for Detection of Hidden Corrosion in Aluminum Plates," Research in Nondestructive Evaluation, 13:61-78.

Volovoi, V.V., Hodges, D.H., Cesnik, C.E.S. and Popescu, B. 2001. "Assessment of Beam Modeling Methods for Rotor Blade Applications," Mathematical and Computer Modeling, 33: 1099-1112.

Wang, K., Inman, D.J. and Farrar, C.R. 2005. "Modeling and Analysis of a Cracked Composite Cantilever Beam Vibrating in Coupled Bending and Torsion," Journal of Sound and Vibration, 284:23-49. 